\title{
Risk Factors for Overweight and Diabetes mellitus in Residential Psychiatric Patients
}

\author{
Evert J. Mookhoek ${ }^{a, b}$ Willem A. de Vries ${ }^{b}$ Johannes E.J.M. Hovens ${ }^{b, c}$ \\ Jacobus R.B.J. Brouwers ${ }^{a}$ Anton J.M. Loonen ${ }^{a, b, d}$ \\ a Division of Pharmacotherapy and Pharmaceutical Care, Department of Pharmacy, University of Groningen, \\ ${ }^{b}$ Delta Psychiatric Centre, Poortugaal, \\ ${ }^{c}$ Institute of Psychology, Erasmus University Rotterdam, \\ ${ }^{d}$ GGZ Westelijk Noord-Brabant, Bergen op Zoom, the Netherlands
}

\section{Keywords \\ Mental disorders - Diabetes mellitus - Clozapine . \\ Overweight · Long-stay}

\section{Summary}

Objective: To investigate the prevalence of and risk factors for overweight and diabetes mellitus in long-stay psychiatric inpatients. Method: Statistical analysis of data collected from medical, laboratory, and pharmacy files. Results: $80 \%$ of the 256 patients were suffering from schizophrenia or other psychotic disorders. The prevalence of diabetes mellitus was $15 \%$. The prevalence of a disturbed glucose tolerance was $14 \%$. Severe overweight (BMI > 30) was positively associated with the use of clozapine (odds ratio $(O R)=2.7 ; 95 \%$ confidence interval $(\mathrm{Cl})$ : $1.31-5.75)$, but negatively with the diagnosis schizophrenia $(\mathrm{OR}=$ $0.4 ; 95 \% \mathrm{Cl}: 0.22-0.88)$. Diabetes mellitus was associated with severe overweight (OR $=3.5 ; 95 \% \mathrm{Cl}: 1.57-7.69$ ). Caucasian patients were at a lower risk for diabetes mellitus (OR $=0.2 ; 95 \% \mathrm{Cl}: 0.08-0.54)$. Conclusions: In residential psychiatric patients, diabetes mellitus is especially associated with overweight and non-Caucasian origin. In this survey, the use of clozapine was associated with overweight, but not directly with diabetes mellitus. Diabetes mellitus is highly prevalent, which calls for screening for diabetes mellitus at regular intervals.

\section{Introduction}

The prevalence of diabetes mellitus in psychiatric patients is higher than that in the general population [1]. This is espe- cially true for schizophrenic patients, who are reported to have diabetes mellitus 2-4 times more often [2]. As early as in the first half of the 20th century, a relationship between psychiatric diseases and diabetes mellitus was suspected [3, 4]. Recently, this hypothesis has been supported by specific reports of an increase in glucose intolerance and insulin resistance in young, drug-naive, schizophrenic patients [5, 6]. The existence of a direct relationship is also supported by other evidence [7]. Psychiatric patients are prone to develop the metabolic syndrome [8]. This is partly due to the influence of atypical anti-psychotic medication, which is associated with the development of overweight, dyslipidemia, and diabetes mellitus type 2 [9].

In long-stay psychiatric inpatients, even more than in the general population of psychiatric patients, the risk factors for diabetes mellitus, such as a sedentary lifestyle, smoking, overweight, and the use of atypical anti-psychotic medication, may coincide. This makes such a patient population particularly suitable to study and distinguish the influence of these factors. As this patient population has as yet not been extensively studied and since the findings may reflect the situation in ambulatory chronic psychiatric patients, we decided to conduct a data survey of a population of long-stay psychiatric inpatients.

\section{Patients and Methods}

All residential patients $(\mathrm{n}=256)$ who were staying in the Delta Psychiatric Center, a general psychiatric hospital of 850 beds in the vicinity of Rotterdam, The Netherlands, were eligible for our study. The center has a catchment area of 650,000 rural and urban inhabitants. Here, an internist and a specialized diabetes nurse practitioner are available for the treatment and coaching of all patients with diabetes mellitus. Body weight

\section{KARGER \\ Fax +497614520714 \\ Information@Karger.de}

www.karger.com (c) 2011 S. Karger GmbH, Freiburg

$1662-4025 / 11 / 0045-0341 \$ 38.00 / 0$

Accessible online at:

www.karger.com/ofa
Prof. Dr. Anton J.M. Loonen

Division of Pharmacotherapy and Pharmaceutical Care

Department of Pharmacy, University of Groningen

Antonius Deusinglaan 1, 9713 AV Groningen, the Netherlands

Tel. + 3150 363-7576, Fax -2772

a.j.m.loonen@rug.nl 
and serum glucose, among other measurements, are recorded at regular intervals in all patients. In patients without diabetes, serum glucose is recorded at least once every year. From the medical, laboratory, and pharmacy files of the 256 residential patients, data were collected on gender, age, ethnicity, psychiatric diagnoses (Diagnostic and Statistical Manual of Mental Disorders fourth edition (DSM-IV)), body mass index (BMI, weight in $\mathrm{kg}$, divided by the square of the height, in $\mathrm{m}^{2}$ ), serum glucose levels, and use of anti-diabetic and anti-psychotic medication.

When a patient used anti-diabetic medication, or had fasting serum glucose levels over $6.9 \mathrm{mmol} / \mathrm{l}$ or non-fasting serum glucose levels over $11.0 \mathrm{mmol} / \mathrm{l}$, he or she was assumed to have diabetes mellitus. When a patient used no anti-diabetic medication and had fasting serum glucose levels between 6.1 and $6.9 \mathrm{mmol} / \mathrm{l}$ or non-fasting serum glucose levels between 7.0 and $11.0 \mathrm{mmol} / \mathrm{l}$, he or she was assumed to have impaired glucose tolerance.

Odds ratios (ORs) were calculated by multiple regression analysis The differences between subgroups were examined with Student's t-test and the chi-square test. The study did not use an external control group. This way, we avoided a number of important confounders, such as housing conditions, income and major differences in lifestyle. Because this is a retrospective survey of medical files, no informed consent or ethical approval was needed for this study.

\section{Results}

On one of the long-stay wards, 256 patients were accommodated. This population consisted of 79 women (31\%) with a mean age of 51 years (standard deviation (SD) 10.7) and 177 men $(69 \%)$ with a mean age of 47 years (SD 12.6). 175 patients $(68 \%)$ suffered from schizophrenia, and 30 patients $(12 \%)$ suffered from a different psychotic disorder. Data on BMI was missing for 10 patients, due to the inability to measure weight and/or height. No recent serum glucose levels were available for 13 patients. 91 patients $(36 \%)$ had severe overweight $(\mathrm{BMI}>30) .39$ patients $(15 \%)$ had diabetes mellitus, and $36(14 \%)$ had disturbed glucose tolerance. 36 of the patients with diabetes had type 2 diabetes mellitus. 42 patients $(16 \%)$ were of non-Caucasian origin. The patient characteristics are summarized in table 1.

Overweight $(\mathrm{BMI}>25)$ was positively associated with the use of clozapine $(\mathrm{OR}=2.5 ; 95 \%$ confidence interval $(\mathrm{CI})$ : $1.12-5.45)$, and negatively with an Asian background (OR = 0.2; 95\% CI: 0.03-0.84). Severe overweight (BMI > 30) was also associated with use of clozapine (OR $=2.7$; $95 \% \mathrm{CI}$ : $1.31-$ 5.75). Patients with schizophrenia had a lower chance of being severely overweight $(\mathrm{OR}=0.4 ; 95 \% \mathrm{CI}$ : $0.22-0.88)$. In table 2, the patients with severe overweight $(\mathrm{BMI}>30)$ are compared with patients without severe overweight $(\mathrm{BMI} \leq 30)$.

In table 3, the patients with diabetes mellitus are compared with patients without diabetes mellitus. Also in the comparison not corrected for overweight, we found no significant differences in the use of atypical anti-psychotic agents. This was also the case when we compared the patients with a normal

Table 1. Patient characteristics

\begin{tabular}{ll}
\hline Characteristic feature & Value \\
\hline Female/male & $79 / 177$ \\
Mean age & 48 years (SD 12.2) \\
Mean length of stay & 12 years (SD 10.4) \\
Main psychiatric diagnosis (DSM-IV axis 1) & \\
$\quad$ Psychotic disorder (schizophrenia 175) & 205 \\
Affective disorder & 23 \\
Addiction & 1 \\
Organic brain disease & 8 \\
Other & 7 \\
No axis 1 diagnoses & 12 \\
\hline
\end{tabular}

Table 2. Contributing factors to overweight*

\begin{tabular}{|c|c|c|c|}
\hline & $\mathrm{BMI} \leq 30$ & $\mathrm{BMI}>30$ & Odds ratio $\mathrm{BMI}>30(\mathrm{CI} 95 \%)$ \\
\hline \multicolumn{4}{|l|}{ Diagnosis } \\
\hline Schizophrenia & $113(67 \%)$ & $56(33 \%)$ & $0.4(0.22-0.88)$ \\
\hline \multicolumn{4}{|l|}{ Medication } \\
\hline Clozapine $^{\mathrm{a}}$ & $60(56 \%)$ & $48(44 \%)$ & $2.7(1.31-5.75)$ \\
\hline Risperidone $^{\mathrm{a}}$ & $22(56 \%)$ & $17(44 \%)$ & $2.1(0.89-4.76)$ \\
\hline Quetiapine $^{\mathrm{a}}$ & $8(53 \%)$ & $7(47 \%)$ & $2.7(0.73-9.73)$ \\
\hline Olanzapine $^{\mathrm{a}}$ & $16(73 \%)$ & $6(27 \%)$ & $1.3(0.37-4.27)$ \\
\hline \multicolumn{4}{|l|}{ Origin } \\
\hline Caucasian & $127(62 \%)$ & $77(38 \%)$ & $0.9(0.40-1.84)$ \\
\hline Hindu & $4(80 \%)$ & $1(20 \%)$ & $0.3(0.03-3.89)$ \\
\hline Mediterranean & $5(71 \%)$ & $2(29 \%)$ & $0.8(0.12-4.69)$ \\
\hline Asian & $7(88 \%)$ & $1(13 \%)$ & $0.4(0.04-3.47)$ \\
\hline Black & $11(50 \%)$ & $11(50 \%)$ & $2.1(0.79-5.36)$ \\
\hline Total & $154(63 \%)$ & $92(37 \%)$ & \\
\hline
\end{tabular}

*The chances of having severe overweight (BMI > 30) were corrected for age, gender, and all variables in this table. Patients with missing data on body weight or body height are not included in these figures.

${ }^{a}$ Some patients used 2 different atypical anti-psychotic agents. 
Table 3. Contributing factors to diabetes*

\begin{tabular}{lrrr}
\hline & No diabetes & Diabetes & Odds ratio (CI 95\%) \\
\hline $\begin{array}{l}\text { Diagnosis } \\
\text { Schizophrenia }\end{array}$ & $147(87 \%)$ & $22(13 \%)$ & $0.7(0.30-1.74)$ \\
BMI & & & \\
$\quad>30$ & $68(75 \%)$ & $23(25 \%)$ & $3.5(1.57-7.69)$ \\
$\quad<25$ & $60(29 \%)$ & $4(10 \%)$ & $0.2(0.05-0.54)$ \\
Medication $^{\text {Clozapine }}$ & & & \\
$\quad$ Risperidone $^{\mathrm{a}}$ & $96(89 \%)$ & $12(11 \%)$ & $0.6(0.23-1.77)$ \\
$\quad$ Quetiapine & $27(69 \%)$ & $12(31 \%)$ & $2.1(0.74-5.75)$ \\
$\quad$ Olanzapine & $12(80 \%)$ & $3(20 \%)$ & $2.0(0.37-10.7)$ \\
Origin $^{\mathrm{a}}$ & $20(91 \%)$ & $2(9 \%)$ & $0.2(0.02-2.20)$ \\
$\quad$ Caucasian & $177(87 \%)$ & $27(13 \%)$ & $0.2(0.08-0.54)$ \\
$\quad$ Hindu & $3(60 \%)$ & $2(40 \%)$ & $5.6(0.60-53.3)$ \\
$\quad$ Mediterranean & $6(86 \%)$ & $1(14 \%)$ & $3.7(0.23-60.6)$ \\
$\quad$ Asian & $6(38 \%)$ & $2(63 \%)$ & $5.4(0.74-39.8)$ \\
$\quad$ Black & $15(68 \%)$ & $7(32 \%)$ & $2.9(0.90-9.07)$ \\
Total & $207(84 \%)$ & $39(16 \%)$ & \\
\hline
\end{tabular}

*The chances of having diabetes mellitus were corrected for age, gender, and all variables in this table. Patients with missing data on body weight or body height are not included in these figures. ${ }^{a}$ Some patients used 2 different atypical anti-psychotic agents.

Table 4. The differences in the use of atypical anti-psychotic agents between the patients with an impaired glucose tolerance, and the patients with diabetes mellitus; influence of atypical anti-psychotics

\begin{tabular}{lcccl}
\hline & Total & $\begin{array}{l}\text { Impaired glucose } \\
\text { tolerance }\end{array}$ & Diabetes & p value (chi-square) \\
\hline Clozapine $^{\mathrm{a}}$ & 108 & $22(20 \%)$ & $12(11 \%)$ & $\mathrm{p}<0.01$ \\
Risperidone $^{\mathrm{a}}$ & 39 & $5(13 \%)$ & $12(31 \%)$ & $\mathrm{ns}$ \\
Quetiapine $^{\mathrm{a}}$ & 15 & $2(13 \%)$ & $3(20 \%)$ & $\mathrm{ns}$ \\
Olanzapine $^{\mathrm{a}}$ & 22 & $4(18 \%)$ & $2(9 \%)$ & $\mathrm{ns}$ \\
\hline
\end{tabular}

${ }^{\text {a }}$ Some patients used 2 different atypical anti-psychotic agents. ns $=$ Not significant. glucose tolerance with patients with an impaired glucose tolerance and patients with diabetes combined. Diabetes mellitus was associated with severe overweight $(\mathrm{OR}=3.5$; $95 \% \mathrm{CI}$ : $1.57-7.69)$. Patients with a BMI $<25$ had a lower probability of being diagnosed with diabetes mellitus ( $\mathrm{OR}=0.2 ; 95 \% \mathrm{CI}$ : $0.05-0.54)$. The same was true for Caucasian patients $(\mathrm{OR}=$ 0.2; 95\% CI: 0.08-0.54).

Table 4 shows the differences in the use of atypical antipsychotic agents between patients with an impaired glucose tolerance and patients diagnosed with diabetes mellitus. Compared to patients with diabetes, patients with an impaired glucose tolerance were significantly $(\mathrm{p}<0.01)$ more often treated with clozapine. There was a tendency for patients with diabetes to be treated more often with risperidone, but this difference was not significant. Patients with a psychotic disorder were more often treated with an atypical anti-psychotic agent than patients with other psychiatric diagnoses $(79 \%$ versus $37 \%$; chi-square $\mathrm{p}<0.001)$. There were no significant differences in the use of atypical anti-psychotic agents between the different ethnic groups.

\section{Discussion}

The prevalences of diabetes mellitus and disturbed glucose tolerance in this population of residential psychiatric patients were $15 \%$ and $14 \%$, respectively. This is comparable to the figures found by Mukherjee et al. [10] in another population of patients with schizophrenia in a long-stay setting. The prevalence of diabetes mellitus that we found is unmistakably higher than the prevalence of nearly $3.5 \%$ for the general Dutch population [11]. The prevalence of severe overweight $(\mathrm{BMI}>30)$ in our population was $36 \%$. This is also substantially higher than in the general adult Dutch population, in which severe overweight was estimated to be approximately $10 \%$ for both men and women [11].

A peculiar finding is that patients with schizophrenia were less frequently severely overweight than patient with a different diagnosis $(\mathrm{OR}=0.4)$. Possibly this can be attributed to the severity of their illness and a relatively poor anti-psychotic treatment response, which results in a high level of psychomotor agitation. 
The relation between overweight and the use of clozapine that we found is well known from the literature [12]. The relation between overweight and the other atypical anti-psychotics was less distinct and not significant. The relative small number of patients in our survey who were receiving other atypical anti-psychotic agents than clozapine limits the conclusions regarding the possible effects of other atypical antipsychotic agents. Contrary to other reports, we found no relation between olanzapine and overweight $[9,13]$. This may be explained by the interventions of the treating physician. Clozapine is a unique anti-psychotic drug that cannot easily be replaced in well-responding schizophrenic patients. Other anti-psychotic drugs do not take such a special position and can more easily be avoided in patients who experience side effects.

Contradictory to other reports, we found no direct relationship between diabetes mellitus and the use of atypical anti-psychotic agents [13-15]. However, in our study, we found a strong relationship between severe overweight and diabetes mellitus. Possibly, the diabetogenic effect of atypical anti-psychotics is mainly mediated by overweight and is not a direct effect of these drugs. This is supported by the findings of Sowell et al. [16] who observed no effects of atypical antipsychotic agents on the glucose metabolism in healthy volunteers. Bushe and Leonard [17] concluded that little evidence exists for a direct diabetogenic effect of atypical anti-psychotics. Taylor et al. [18] warned of the possible bias caused by a more frequent monitoring of glucose metabolism in patients treated with the atypical anti-psychotic agents. It could even be argued that the relation between atypical anti-psychotics and overweight is not a result of metabolic effects of the atypical anti-psychotics themselves, but that it is a result of the absence of rigidity and involuntary movements as part of extra-pyramidal movement disorders caused by the older anti-psychotic agents. Notwithstanding the unhealthy nature of this way of exercising, these movement disorders may have prevented overweight by increasing muscular energy consumption. This may also explain our finding that patients with schizophrenia had a lower chance of being severely overweight. Possibly, the patients with schizophrenia received older anti-psychotic agents more often than the patients with other psychiatric diagnosis.

In our survey, non-Caucasian patients were more prone to develop diabetes mellitus than Caucasian patients, who had the lowest OR for diabetes mellitus. Cappucio et al. [19] found diabetes to occur more frequently among South Asians and West Africans. Other authors also found ethnic differences in the prevalence of diabetes [20,21]. They explained these differences, partially, with differences in socio-economic status, level of education, and lifestyle factors. However, these factors are far less important in a population of patients admitted to long-stay wards. Besides a significantly lower rate of overweight in patients of Asian background, we found no differences in BMI between the ethnic groups in our survey. The ethnic differences we found in the prevalence of diabetes can probably be attributed to genetic or developmental factors.

Diabetes in psychiatric patients is associated with an increased mortality rate $[22,23]$. Furthermore, comorbid disease is associated with a reduction in the quality of life. This underscores the importance of preventing diabetes. Overweight is the most promising target in the prevention of type 2 diabetes mellitus in this group of patients. As in non-psychiatric patients, physical exercise and dietary measures are the two most important approaches for treatment and prevention [24, 25]. Richardson et al. [26] argued for integrating physical activities in psychiatric treatment programs. That this is difficult was illustrated by Ussher [27], who described an ambivalent attitude in psychiatric patients towards physical exercise. In addition, the effect, size and duration of lifestyle interventions are often limited [28]. Therefore, we favor research into more effective ways to prevent and treat obesity in psychiatric patients. For instance, Wu et al. [29] found that metformin treatment by itself was superior to lifestyle interventions for anti-psychotic agent-induced weight gain. They found a combination of metformin treatment and lifestyle interventions to be most effective.

\section{Conclusions}

In a population of residential psychiatric patients, we found the prevalence of diabetes mellitus to be $15 \%$. The results do not support the existence of a direct association between diabetes mellitus and atypical anti-psychotic agents. We did find an association between clozapine and overweight. Risk factors for diabetes mellitus are overweight and non-Caucasian origin.

\section{Disclosure Statement}

The authors declared no conflict of interest. 


\section{References}

1 Cassidy F, Ahearn E, Carroll BJ: Elevated frequency of diabetes mellitus in hospitalized manicdepressive patients. Am J Psychiatry 1999;156: $1417-1420$.

2 Bushe C, Holt R: Prevalence of diabetes and impaired glucose tolerance in patients with schizophrenia. Br J Psychiatry 2004;184(suppl 47):s67s71.

- 3 Freeman H, Rodnick EH, Shakow D, Lebeaux T: The carbohydrate tolerance of mentally disturbed soldiers. Psychosom Med 1944;6:311-317.

4 Kohen D: Diabetes mellitus and schizophrenia: historical perspective. Br J Psychiatry 2004;184(suppl 47):s64-s66.

5 Nimwegen LJM van, Storosum JG, Blumer RME, Allick G, Venema HW, de Haan L, Becker H, van Amelsvoort T, Ackermans MT, Fliers E, Serlie MJ, Sauerwein HP: Hepatic insulin resistance in antipsychotic naïve schizophrenic patients: stable isotope studies of glucose metabolism. J Clin Endocrinol Metab 2008;93:572-577.

6 Ryan MCM, Collins P, Thakore JH: Impaired fasting glucose tolerance in first-episode drug-naive patients with schizophrenia. Am J Psychiatry 2003; 160:284-289.

7 Thakore JH: Metabolic disturbance in first-episode schizophrenia. Br J Psychiatry 2004;184(suppl 47): s76-s79.

8 Schorr SG, Slooff CJ, Bruggeman R, Taxis K: The incidence of metabolic syndrome and its reversal in a cohort of schizophrenic patients followed for one year. J Psychiatr Res 2009;43:1106-1111.

$\checkmark 9$ Cohen D: Atypical antipsychotics and new onset diabetes mellitus. Pharmacopsychiatry 2004;37:111.

10 Mukherjee S, Decina P, Bocola V, Saraceni F, Scapicchio PL: Diabetes mellitus in schizophrenic patients. Compr Psychiatry 1996;37:68-73.

11 CBS (Central Bureau Statistics): Health and Healthcare in Numbers 2007 (Gezondheid en zorg in cijfers 2007). Voorburg/Heerlen, Centraal Bureau Statistiek, 2007, pp 77, 117.

12 Henderson DC, Cagliero E, Gray C, Nasrallah RA, Hayden DL, Schoenfeld DA, et al.: Clozapine, diabetes mellitus, weight gain and lipid abnormalities: a five-year naturalistic study. Am J Psychiatry 2000;157:975-981.

13 Gianfrancesco F, White R, Wang R, Nasrallah HA Antipsychotic-induced type 2 diabetes: evidence from a large health plan database. J Clin Psychopharmacol 2003;23:328-335.

14 Henderson DC, Cagliero E, Copeland PM, Borba CP, Evins E, Hayden D, Weber MT, Anderson EJ, Allison DB, Daley TB, Schoenfeld D, Goff DC: Glucose metabolism in patients with schizophrenia treated with atypical antipsychotic agents. Arch Gen Psychiatry 2005;62:19-28.

-15 Sernyak MJ, Leslie DL, Alarcon RD, Losonczy MF, Rosenheck R: Association of diabetes mellitus with use of atypical neuroleptics in the treatment of schizophrenia. Am J Psychiatry 2002;159:561-566.

16 Sowell MO, Mukhopadhyay N, Cavazzoni P, Shankar S, Steinberg HO, Breier A, Beasley CM $\mathrm{Jr}$, Dananberg J: Hyperglycemic clamp assessment of insulin secretory responses in normal subjects treated with olanzapine, risperidone or placebo. J Clin Endocrinol Metab 2002;87:2918-2923.

17 Bushe C, Leonard B: Association between atypical antipsychotic agents and type 2 diabetes: review of prospective clinical data. Br J Psychiatry 2004;184(suppl 47):s87-s93.
18 Taylor D, Young C, Esop R, Paton C, Walwyn R: Testing for diabetes in hospitalized patients prescribed antipsychotic drug. Br J Psychiatry 2004; 185:152-156.

19 Cappuccio FP, Cook DG, Atkinson RW, Strazullo P: Prevalence, detection, and management of cardiovascular risk factors in different ethnic groups in south London. Heart 1997;78:555-563.

20 Cossrow N, Falkner B: Race/ethnic issues in obesity and obesity-related comorbidity. J Clin Endocrinol Metab 2004;89:2590-2594.

21 Lindquist CH, Gower BA, Goran MI: Role of dietary factors in ethnic differences in early risk of cardiovascular disease and type 2 diabetes. Am J Clin Nutr 2000;71:725-732.

22 Jackson CT, Covell NH, Drake RE, Essock SM: Relationship between diabetes and mortality among persons with co-occurring psychotic and substance use disorders. Psychiatr Serv 2007;58:270-272.

23 Correll CU, Frederickson AM, Kane JM, Manu P: Metabolic syndrome and the risk of coronary heart disease in 367 patients treated with second-generation antipsychotic drugs. J Clin Psychiatry 2006; 67:575-583.

24 Tuomilehto J, Lindström J, Eriksson JG, Valle TT, Hämäläinen H, Ilanne-Parikka P, Keinänen-Kiukaanniemi S, Laakso M, Louheranta A, Rastas M, Salminen V, Uusitupa M; Finnish Diabetes Prevention Study Group: Prevention of type 2 diabetes mellitus by changes in lifestyle among subjects with impaired glucose tolerance. N Engl J Med 2001; 344:1343-1350.

25 Faulkner G, Soundy AA, Lloyd K: Schizophrenia and weight management: a systematic review of interventions to control weight. Acta Psychiatr Scand 2003;108:324-332.

26 Richardson CR, Faulkner G, McDevitt J, Skrinar GS, Hutchinson DS, Piette JD: Integrating physical activity into mental health services for persons with serious mental illness. Psychiatr Serv 2005;56:324331.

27 Ussher M, Stanbury L, Cheeseman V, Faulkner G: Physical activity preferences and perceived barriers to activity among persons with severe mental illness in the United Kingdom. Psychiatr Serv 2007;58: 405-408.

28 McCreadie RG, Kelly C, Connoly M, Williams S, Baxter G, Lean M, Paterson JR: Dietary improvement in people with schizophrenia. Br J Psychiatry 2005;187:346-351.

29 Wu RR, Zhao JP, Jin H, Shao P, Fang MS, Guo XF, He YQ, Liu YJ, Chen JD, Li LH: Lifestyle intervention and metformin for treatment of antipsychotic-induced weight gain. JAMA 2008;299: 185-193. 